\title{
A introdução do juiz das garantias no Brasil e o inquérito policial eletrônico
}

\author{
The introduction of the guarantee judge in Brazil \\ and the electronic police inquiry
}

Rodrigo Régnier Chemim Guimarães ${ }^{1}$
Universidade Positivo - Curitiba/PR, Brasil
rodrigo.chemim@up.edu.br
9 http://lattes.cnpq.br/3509382891487960
(1) https://orcid.org/0000-0001-7378-4553

Sarah Gonçalves Ribeiro ${ }^{2}$

Fundação Escola do Ministério Público do Estado do Paraná - Curitiba/PR, Brasil ribeirogsarah@gmail.com

http://lattes.cnpq.br/1023020248431150

https://orcid.org/0000-0001-5573-2506

Resumo: Considera-se "juiz das garantias" o magistrado que atua apenas na fase de investigação, avaliando a legalidade dos atos e decidindo medidas cautelares pessoais e reais. Sua adoção procura evitar a contaminação psicológica do magistrado que julgará eventual processo. Introduzido, no Brasil, pela Lei 13.964/2019, está sendo questionado em quatro ações diretas de inconstitucionalidade. Em decisão liminar, o ministro Fux acolheu a pretensão de suspensão das regras inseridas no Código de Processo Penal, por período indeterminado. Dentre

1 Doutor em Direito de Estado pela Universidade Federal do Paraná. Professor Titular de Direito Processual Penal da Escola de Direito e do Programa de Mestrado Profissional em Direito da Universidade Positivo. Procurador de Justiça do Ministério Público do Estado do Paraná.

2 Cursando pós-graduação e especialização de Direito na Fundação Escola do Ministério Público do Estado do Paraná, e, em Penal e Processo Penal na Universidade Curitiba. Graduada em direito na Universidade Positivo. Cursando Filosofia na Faculdade Claretiano. 
elas, o art. $3^{\circ}-D$, que propõe a criação de um sistema de rodízio de magistrados nas comarcas em que funcionar apenas um juiz, como solução para a viabilizar a presença do "juiz das garantias" no interior do país. $\mathrm{O}$ argumento central para essa decisão, foi a indevida ingerência do Poder Legislativo na autonomia orçamentária e de auto-gestão do Judiciário, somada, tanto ao elevado custo de contratação de novos magistrados, promotores, delegados e defensores públicos, quanto aos gastos rotineiros com diárias em deslocamentos físicos destes profissionais. O presente artigo visa a apresentar a adoção do inquérito policial eletrônico como atenuante para os custos de implantação do "juiz das garantias" no Brasil, neutralizando a discussão de constitucionalidade do art. $3^{\circ}$-D no Supremo Tribunal Federal.

Palavras-Chave: inquérito policial; investigação policial; juiz das garantias; inquérito policial eletrônico.

Aвstract: A "judge of guarantees" is a magistrate who acts only in the investigation phase, assessing the legality of the acts and deciding personal and real precautionary measures. Its adoption seeks to avoid psychological contamination of the magistrate, who will judge an eventual process. Introduced in Brazil by Law 13.964/2019, it is being challenged in four direct actions of unconstitutionality. In a preliminary decision, minister Fux accepted the intention to suspend the rules included in the Code of Criminal Procedure, for an indefinite period. Among them, art. $3^{\circ}-D$, which proposes the creation of a system of rotation of magistrates in the counties where only one judge works, as a solution to make the presence of the "judge of guarantees" feasible in the interior of the country. The central argument for this decision was the undue interference of the Legislative Power in the budgetary autonomy and self-management of the Judiciary, added, both to the high cost of hiring new magistrates, prosecutors, police officers and public defenders, as well as the routine expenses with daily physical displacement of these professionals. This article aims to present the adoption of the electronic police inquiry as a mitigation for the costs of implantation of the "judge of guarantees" in Brazil, neutralizing the discussion of the constitutionality of art. 3rd-D in the Federal Supreme Court.

KEYWORDs: police investigation; judge of guarantees; police inquiry; electronic police inquiry.

SUMÁRIo: Introdução; 1. Os avanços tecnológicos no processo penal brasileiro em torno dos registros de atos processuais e de 
investigação e a dificuldade de adaptação dos atores processuais; 2. As iniciativas pioneiras de implantação do inquérito policial eletrônico; 3. A introdução do juiz das garantias no Brasil; 4. Vantagens econômicas do inquérito policial eletrônico; Considerações Finais; Referências.

\section{INTRODUÇão}

No início do século passado, os registros de atos processuais passaram por uma discussão em torno da possibilidade de se utilizar a máquina de escrever em substituição à grafia de próprio punho das autoridades. Havia dúvida quanto à autenticidade do documento, que se resolveu pela exigência das assinaturas físicas como chancelas do resultado da datilografia. As mudanças tecnológicas não aconteciam com frequência e, assim, eram incorporadas à legislação em ritmo que permitia adaptação paulatina dos atores processuais. Cem anos depois, a tecnologia acelerou o processo de mudanças e avançou em velocidade que muitas vezes não consegue ser acompanhada pelo legislador e pelas práticas judiciárias. Nos primeiros vinte anos do século XXI, boa parte dos processos e documentos físicos já migrou para o modelo virtual no Brasil, validados por assinaturas eletrônicas e armazenados virtualmente numa rede de computadores, mas ainda não se aproveitou toda a potencialidade de utilização das novas tecnologias disponíveis para a fase pré-processual.

Para que se tenha dimensão do quanto se pode melhorar o sistema de investigação e controle, foi apenas em 2016, quase oito décadas após a promulgação do Código de Processo Penal de 1941, que se passou a discutir a necessidade de digitalizar a tramitação do inquérito policial no Brasil.

O tema, agora, ganha uma nova dimensão de importância, quando se correlaciona, diretamente, com a novidade do juiz das garantias, trazida pela Lei 13.964/2019, que introduziu os artigos $3^{\circ}-\mathrm{B}$ a $3^{\circ}-\mathrm{F}$, no Código de Processo Penal, e definiu o "juiz das garantias" como sendo o "responsável pelo controle da legalidade da investigação criminal e pela salvaguarda dos direitos individuais cuja franquia tenha sido reservada à autorização 
prévia do Poder Judiciário"3. A ideia é que o juiz da fase da investigação não seja o mesmo que atua na fase de julgamento do processo, evitando, assim, a possível influência psicológica que as decisões proferidas no inquérito policial possam causar no juiz ao sentenciar o caso.

Apesar do modelo de "juiz das garantias" já ter sido implantado em diversos países no mundo ${ }^{4}$, no Brasil a adoção desse mecanismo de garantia vem sofrendo rejeições. Foram propostas quatro ações diretas

3 BRASIL. Presidência da República. Lei 13.964/2019. Disponível em http:// www.planalto.gov.br/ccivil_03/_ato2019-2022/2019/lei/L13964.htm, acesso em 15 de janeiro de 2020.

4 Nem todos os países europeus e latino-americanos adotam o modelo. A Espanha, por exemplo, tem o chamado "juez de instruccion", porém, ele mistura atividade investigativa com garantias e atuaria em modelo que não separa essas funções. Em relação ao modelo espanhol, Aury Lopes Jr. e Ricardo Jacobsen Gloeckner esclarecem que "em que pese o fortalecimento do promotor na investigação preliminar, a $\mathrm{LO}$ n. 78/88 não rompeu de vez com a tradição do juiz instrutor e, inclusive, previu o legislador que o procedimento judicial a cargo do juiz deverá prevalecer sobre aquele realizado pelo promotor" (LOPES JR., Aury; GLOECKNER, Ricardo Jacobsen. Investigação Preliminar no Processo Penal. $5^{\mathrm{a} e d .}$., São Paulo: Saraiva, 2013, p. 362). Na América Latina, a Argentina tem modelo federal similar ao da Espanha, com juiz investigador, salvo em algumas Províncias, a exemplo de Entre Ríos e Paraná, que têm autonomia legislativa e vem implantando há alguns anos o modelo de juiz de garantias. Já outros países separam as funções de investigar e atuar como garante dos direitos dos cidadãos, inclusive com separação das funções jurisdicionais na fase de investigação e na fase de julgamento processual, a exemplo do que ocorre na Itália, desde 1989, conforme o art. 328, do Codice di Procedura Penale (ITALIA, Codice di procedura penale e leggi complementari. Giurisprudenza, schemi e tabelle. A cura di Aurelio Barazzetta e Renato Bricchetti, Milano: Gruppo 24ore, 2012, p, 161); na França, desde o ano 2000, com a Lei 200-516, que inseriu o artigo 137-1 no Code de Procédure Pénale (FRANÇA. Códe de Procédure Pénale. Disponível em https://www.legifrance.gouv.fr/affichCodeArticle.do?cidTexte=LEGITEXT000006071154\&idArticle=LEGIARTI000033551641, acesso em 25 de fevereiro de 2020); no Chile, com implantação gradual, entre 2000 e 2005, conforme os arts. $9^{\circ}$ e 70, do Codigo Procesal Penal chileno (CHILE. Codigo Procesal Penal del Chile. Disponível em https://www. leychile.cl/Navegar?idNorma=176595\#garant\%C3\%ADas2, acesso em 25 de fevereiro de 2020); no Paraguai, desde 1998, conforme o art. 282, do Código Procesal Penal del Paraguay (PARAGUAI. Codigo Procesal Penal de la República del Paraguay. Disponível em https://www.pj.gov.py/ebook/ libros_files/Coleccion_de_Derecho_Penal_TomoIII.pdf, acesso em 25 de fevereiro de 2020); na Colômbia, desde 2002, com a alteração do artigo 250 da Constituição colombiana (COLOMBIA. Acto legislativo 3 de 2002. 
de inconstitucionalidade no Supremo Tribunal Federal ${ }^{5} \mathrm{e}$ a mais debatida delas foi a de $\mathrm{n}^{0}$ 6.298, ajuizada pela Associação dos Magistrados Brasileiros (AMB). Uma das alegações feitas foi a inviabilidade financeira para a aplicação do juiz das garantias no Brasil.

Antes mesmo da lei entrar em vigor, em 15 de janeiro de 2020, o ministro Dias Toffoli, presidente do STF, concedeu liminar nessa ação para suspender a eficácia dos artigos que implantaram o juiz das garantias, ou seja, os artigos $3^{\circ}-\mathrm{B}, 3^{\circ}-\mathrm{C}, 3^{\circ}$-D, “caput” e seu parágrafo único, $3^{\circ}$-E e $3^{\circ}$ F, do CPP, inseridos pela Lei n ${ }^{\circ} 13.964 / 2019$. Decidiu, também, ampliar para 180 dias a vacatio legis ${ }^{6}$. Poucos dias depois, em 22 de janeiro de 2020, o ministro relator das quatro ADIs, Luiz Fux, ampliou a suspensão da eficácia dos referidos artigos, sine die $e^{7}$. Nessas duas decisões, o que merece destaque, é a suspensão da eficácia do parágrafo único do artigo $3^{\circ}-\mathrm{D}^{8}$, que visa apresentar uma solução para a implantação do juiz das garantias nas comarcas do interior do país, particularmente naquelas em que funciona apenas um juiz, estabelecendo que "os tribunais criarão um sistema de rodízio de magistrados”. Nesse ponto, os ministros acolheram a linha de argumentação da Associação Nacional dos Magistrados: a lei promove uma interferência indevida na auto-organização do Poder Judiciário, violando, ainda, a sua autonomia orçamentária. Consideraram que

Disponível em https://www.funcionpublica.gov.co/eva/gestornormativo/ norma.php?i=6679, acesso em 25 de fevereiro de 2020).

5 ADIs $\mathrm{n}^{0}$ 6.298, ajuizada pela Associação Nacional dos Magistrados; $\mathrm{n}^{0}$ 6.299, ajuizada pelos partidos políticos Podemos e Cidadania; $\mathrm{n}^{\circ} 6.300$, ajuizada pelo partido político Partido Social Liberal e $\mathrm{n}^{0} 6.305$, ajuizada pela CONAMP Associação Nacional dos Membros do Ministério Público.

6 BRASIL. Supremo Tribunal Federal. Medida Cautelar na Ação Direta de Inconstitucionalidade 6.298. Disponível em http://www.stf.jus.br/arquivo/ $\mathrm{cms} /$ noticiaNoticiaStf/anexo/Juizdasgarantias.pdf, acesso em 15 de janeiro de 2020.

7 BRASIL. Supremo Tribunal Federal. Medida Cautelar na Ação Direta de Inconstitucionalidade 6.298. Relator ministro Luiz Fux. Disponível em https:// www.stf.jus.br/arquivo/cms/noticiaNoticiaStf/anexo/ADI6298.pdf, acesso em 23 de janeiro de 2020.

8 Art. $3^{\circ}$-D (...) Parágrafo único. Nas comarcas em que funcionar apenas um juiz, os tribunais criarão um sistema de rodízio de magistrados, a fim de atender às disposições deste Capítulo. 
não há previsão orçamentária para ampliar os gastos com novos juízes e com deslocamentos e diárias de juízes nas comarcas do interior do país ${ }^{9}$.

Este artigo visa a apresentar a utilização do inquérito policial eletrônico como atenuante para esse que é um dos principais empecilhos apresentadas à implantação do juiz das garantias no Brasil: a dificuldade orçamentária. Sabe-se que os argumentos lançados nas ADIs propostas no Supremo Tribunal Federal vão além desse ponto, mas, para efeitos deste artigo, pretende-se focar a discussão na não interferência de autonomia do Poder Judiciário e na viabilidade orçamentária de implantação do juiz das garantias com o auxílio da tecnologia e com a implantação do inquérito policial eletrônico em todos os Estados brasileiros. As questões que se pretende responder, portanto, são centradas nos seguintes pontos: é possível reverter as críticas da AMB em torno da implantação do juiz das garantias no que diz respeito às restrições orçamentárias através do uso da tecnologia na fase de investigação? O custo de implantação do inquérito policial eletrônico é mais baixo do que a contratação de novos juízes e

9 AMB - Associação dos Magistrados Brasileiros. Disponível em https:// www.amb.com.br/wp-content/uploads/2019/12/ADI-AMB-e-Ajufe-juizde-garantias.pdf, acesso em 28 de fevereiro de 2020. Da petição inicial da ADI, extraem-se as seguintes ilustradoras passagens desse reclamo: "Se a Justiça Criminal brasileira sofre severas críticas, especialmente quanto a fase investigatória, porque depende para o seu efetivo funcionamento de uma polícia judiciária eficaz -- que não existe --, agora, com a instituição do "Juiz das Garantias", dificilmente os inquéritos chegarão a um bom termo, em prazo razoável, porque no momento em que houver a provocação por parte das autoridades policiais ou do Ministério Público, visando a obter provimento judicial necessário à instrução dos inquéritos, não haverá magistrado em número suficiente para atender a demanda. Aí está o dano maior causado pela criação do "Juiz das Garantias", no plano da política judiciária, porque o Poder Judiciário brasileiro não possui estrutura suficiente para a sua implementação e funcionamento regular.” (...) “As normas aqui impugnadas estão, ainda, violando claramente o disposto no art. 169 da CF, porque, por maior que seja a criatividade de gestão dos Tribunais, não há como dar execução à Lei do Juiz das Garantias sem provocar aumento de despesas." (...) "Mesmo essa solução de "rodízio de magistrados" implica aumento de gastos, porque pressupõe deslocamento, com pagamento de verbas assessórias para permitir o exercício da jurisdição fora da residência da comarca. Haverá aumento de gastos com a solução final -criação de cargos -- e aumento de gastos desde logo, com descolamentos de juízes, sem que tivesse havido previsão orçamentária, e, portanto, com ofensa ao art. 169 da CF”. 
gastos com diárias de deslocamento de magistrados, promotores, delegados e defensores públicos? A adoção do inquérito policial eletrônico, como medida a contribuir para a implantação do juiz das garantias no Brasil, depende da definição que se dará em torno da constitucionalidade do parágrafo único do artigo $3^{\circ}-\mathrm{D}$, do Código de Processo Penal?

A principal preocupação é que o abandono do juiz das garantias possa trazer retrocesso ao progresso democrático do processo penal brasileiro. Sendo assim, discute-se, neste artigo, a viabilidade de substituir a presença física pela virtual do magistrado no acompanhamento e fiscalização da legalidade e das garantias dos cidadãos nas investigações criminais, sem custos elevados para o Estado.

\section{Os aVANÇOS TECNOLÓgICOS NO PROCESSO PENAL BRASILEIRO EM TORNO DOS REGISTROS DE ATOS PROCESSUAIS E DE INVESTIGAÇÃO E A DIFICULDADE DE ADAPTAÇÃO DOS ATORES PROCESSUAIS.}

Durante séculos, a par dos processos orais, sem assento documental algum, quando se procurava registrar algum ato de investigação ou processual, a forma escrita em pergaminhos, papéis ou livros, foi praticamente a única disponível. A primeira grande novidade tecnológica na forma do registro e documentação de atos jurídicos disponível ao público surgiu apenas 1873 , representada pela máquina de escrever ${ }^{10}$. No Brasil, as máquinas começaram a ser importadas na primeira metade do século XX, iniciando um lento processo de adaptação que provocou mudanças práticas, não sem sofrer naturais aversões por parte de quem não se sentia à vontade com a novidade ${ }^{11}$.

Tanto as mudanças de comportamento e adaptação provocadas pela nova tecnologia quanto a resistência ao seu uso não foram exclusividades do direito, por evidente. O Jornal do Brasil, por exemplo, adquiriu,

10 ZELLERS, John Adam. The Typewriter. A short History on its 75th Anniversary, 1873-1948. New York: Newcomen Society of England. American Brench, 1948, p. 14.

11 SUSSEKIND, Flora. Cinematógrafo de Letras: literatura, técnica e modernização no Brasil. São Paulo: Companhia das Letras, 1987, p. 94. 
em $1912^{12}$, suas três primeiras máquinas de escrever, mas os jornalistas reagiram negativamente à novidade, acostumados que estavam a usar a caneta bico de pena para redigir as matérias ${ }^{13}$. Da mesma forma sucedeu com o registro e a documentação de atos processuais, feitos de forma manuscrita e por quem estava acostumado com essa prática ${ }^{14}$. Ademais, a grafia estampada no papel dava autenticidade ao documento, pois se sabia que a letra era oriunda do punho subscritor de uma determinada pessoa e com a máquina de escrever não era mais possível dizer quem foi que dela se utilizou, já que qualquer pessoa que apertasse o botão provocava igual impressão da letra no papel. Mesmo assim, ela foi ganhando espaço nos escritórios, no foro e nas delegacias de polícia. A mudança chegou a ser debatida nos tribunais brasileiros, tendo prevalecido o entendimento de que era possível aceitar essa nova tecnologia, desde que os atos do delegado de polícia e dos demais atores jurídicos viessem acompanhados da assinatura ou rubrica do autor do ato ${ }^{15}$.

Atento à mudança tecnológica e cultural, o legislador brasileiro, em 1941, regrou a questão no artigo $9^{\circ}$ do vetusto Código de Processo Penal, ainda vigente, onde se lê: "Todas as peças do inquérito policial serão, num só processado, reduzidas a escrito ou datilografadas e, neste caso, rubricadas pela autoridade." O texto é sintomático, pois revela uma preocupação em regrar expressamente a aceitação de peças de investigação datilografadas.

12 BARBOSA, Marialva. História Cultural da Imprensa. Brasil. 1900-2000. Rio de Janeiro: Mauad, 2007, p. 37.

13 CADENA, Nelson Váron. O impacto das máquinas de escrever nas redações. In: Portal Imprensa. 27 de outubro de 2008, disponível em http://portalimprensa.com.br/noticias/opiniao/311/o+impacto+da+maquina+de+escrever+nas+redacoes, acesso em 14 de janeiro de 2020.

14 No Tribunal de Justiça do Paraná, a primeira máquina de escrever foi adquirida em 1915 e utilizada pela secretaria do Tribunal. Conforme noticiado em ESTADO DO PARANÀ. Tribunal de Justiça. A evolução da escrita e da comunicação no Poder Judiciário do Paraná é tema de exposição. Disponível em https://www.tjpr.jus.br/noticias/-/asset_publisher/9jZB/content/a-evolucao-da-escrita-e-da-comunicacao-no-poder-judiciario-do-parana-e-tema-de-exposicao/18319?inheritRedirect=false, acesso em 28 de fevereiro de 2020.

15 No mesmo sentido, o relato de CHOUKR, Fauzi Hassan. Código de Processo Penal: comentários consolidados e crítica jurisprudencial. $3^{\mathrm{a}}$ ed., São Paulo: Saraiva, 2009, p. 355. 
A máquina de escrever permaneceu sendo a tecnologia dominante utilizada ao longo das décadas seguintes ${ }^{16}$. Apenas por volta de 1987, é que o computador, ainda um invento muito caro e de difícil acesso no mercado interno, começou a ser utilizado em alguns escritórios de advocacia, por iniciativa de uma nova geração de advogados mais receptivos às novidades tecnológicas ${ }^{17}$. Os primeiros computadores de uso doméstico se popularizaram no Brasil em meados dos anos 1990, e demoraram outros dez anos para começar a chegar às delegacias de polícia, notadamente as estaduais, quase invariavelmente desestruturadas pelo desinteresse dos governadores ${ }^{18}$. Em rápida pesquisa na internet não é difícil encontrar notícias dando conta de que, em 2013, ainda existiam delegacias de polícia no Brasil cujo equipamento utilizado era a máquina de escrever ${ }^{19}$.

16 Nos anos 1960 ela ganhou versões elétricas que somente se popularizam por aqui nos anos 1970 em diante, com a máquina desenvolvida pela IBM, a qual dava maior agilidade à escrita, pois utilizava uma cabeça de caracteres em substituição aos braços das letras que vinham configurados em forma da tradicional "cesta", além de ser mais silenciosa e facilitar a datilografia, pois era mais leve no toque da tecla, não precisando voltar o carro ao final da linha. Nos anos 1980 ocorre outro pequeno avanço tecnológico e surgem os modelos eletrônicos mais sofisticados da máquina de escrever, capazes de realizar a escrita de uma linha inteira numa pequena tela na própria máquina, permitindo a correção de uma frase antes de sua impressão no papel.

17 É certo que um ou outro computador foi adquirido antes dessa data, a exemplo do primeiro computador do Tribunal de Justiça do Paraná, comprado em 1972, mas a tecnologia era ainda muito precária e de pouca utilidade. Depois da metade dos anos 1980 é que seu uso começou a ganhar popularidade. Conforme noticiado em ESTADO DO PARANÀ. Tribunal de Justiça. A evolução da escrita e da comunicação no Poder Judiciário do Paraná é tema de exposição. Disponível em https://www.tjpr.jus.br/noticias/-/asset_publisher/9jZB/ content/a-evolucao-da-escrita-e-da-comunicacao-no-poder-judiciario-do -parana-e-tema-de-exposicao/18319?inheritRedirect=false, acesso em 28 de fevereiro de 2020.

18 FURTADO, Vasco. Tecnologia e Gestão da Informação na Segurança Pública. São Paulo: Garamond, 2002, p. 125.

19 SOARES, Rafael. Delegacia da Baixada Fluminense ainda usa máquina de escrever e tem mofo nas paredes. In: Jornal Extra. Edição de 31 de março de 2013, disponível em https://extra.globo.com/casos-de-policia/delegaciada-baixada-fluminense-ainda-usa-maquina-de-escrever-tem-mofo-nas-paredes-7985826.html, acesso em 14 de janeiro de 2020. 
No início, os computadores ainda eram muito lentos, com pouquíssimos recursos e praticamente agiam como uma máquina de escrever sofisticada, capaz de escrever e apagar textos inteiros, deslocar trechos de um texto de um lugar para outro e reorganizá-los antes de processar sua impressão em enormes impressoras matriciais. Além disso, permitiam que os textos fossem arquivados em memórias internas ou transportáveis. Dito assim parece pouco, mas, na verdade, as mudanças foram de grande monta, principalmente na qualidade e rapidez da escrita, bem como na capacidade de produção de textos-padrão em série.

Ainda em meados dos anos 1990, nem bem se tinha assimilado e popularizado a mudança da máquina de escrever manual para aquela eletrônica e desta para o computador, a internet se expandiu no Brasil ${ }^{20}$, provocando mudança paradigmática na pesquisa acadêmica, de legislação, de doutrina e de jurisprudência ${ }^{21}$.

O que se percebe nesse desenvolvimento é que a tecnologia caminhou nos últimos trinta anos, em novo compasso, evoluindo agora em ritmo acelerado. Praticamente a cada ano surgiu uma novidade

20 Como esclarece Rita de Cássia Lopes da Silva, a internet chegou no Brasil em 1988 por iniciativa da Fundação de Amparo à Pesquisa do Estado de São Paulo (Fapesp), da Universidade Federal do Rio de Janeiro e do Laboratório Nacional de Computação Científica, sendo que em 1990 o Ministério de Ciências e Tecnologia, em conjunto com o Ministério da Educação, criou o "backbone" Rede Nacional de Pesquisas (RNP), interligando 11 Estados e suas capitais. Ainda segundo a mesma autora, "em 1992 foi instalada a primeira espinha dorsal conectada à internet nas principais universidades e centros de pesquisa do País, além de algumas organizações não-governamentais" (SILVA, Rita de Cássia Lopes da. Direito Penal e Sistema Informático. São Paulo: RT, 2003, pp. 23-24).

21 Se antes, para pesquisar uma decisão de um Tribunal era preciso ter a sorte de encontrá-la previamente selecionada em repositórios oficiais de jurisprudência como a Revista dos Tribunais (publicada bimestralmente e adquirida por assinatura), ou ir pessoalmente à biblioteca dos Tribunais para fazer pesquisa "in loco", baixando arquivos de acórdãos das prateleiras, agora basta digitar os verbetes alusivos ao tema na página da internet do tribunal para ter acesso a todos os julgados a respeito daquele tema. Quanto à doutrina o acesso era igualmente dificultado e limitado, principalmente para quem residia longe dos grandes centros e não contava com nenhuma biblioteca ou livraria por perto, ficando na dependência de um livreiro errante passar pela Comarca com ofertas de livros no porta-malas do automóvel... 
revolucionária em termos de atualização de hardware, programas de software, novas capacidades de memória e arquivos. Do floppy-disk de 8 polegadas, passando por aquele de 5 e $1 / 4$, ao disquete de 3 polegadas e meia, aos cartões de memória, ao CD-R, ao CD-RW, ao DVD-R, às entradas USB, ao pen drive, HDs externos, discos ópticos, até o armazenamento na nuvem e o uso de computadores em rede, tudo foi muito rápido. Soma-se a isso o avanço exponencial no desenvolvimento e no uso dos aparelhos celulares smartphones conectados à internet, com aplicativos internos de scanner e variadas ferramentas de comunicação virtual.

As mudanças foram tão aceleradas que boa parte das gerações mais antigas de advogados, delegados, promotores e juízes, nascidas antes dos anos 1950, que viveram praticamente suas carreiras inteiras tendo que se adaptar apenas a uma nova tecnologia representada pela máquina de escrever, tiveram dificuldades de acompanhar toda essa evolução. O ritmo apressado do desenvolvimento tecnológico era - e ainda é - de tal ordem que algumas tecnologias, a exemplo do aparelho de fac-símile usado para enviar e protocolizar petições, por exemplo, foram quase que simultaneamente tão revolucionárias quanto se tornaram obsoletas.

O impacto nas polícias judiciárias, no entanto, foi sempre mais lento e os computadores seguiram por um bom tempo sendo usados mais como máquinas de escrever sofisticadas do que para agilizar as investigações criminais ou mesmo para facilitar o contato e aproximar as demais instâncias formais de controle da criminalidade.

Hoje o grande desafio está sendo conseguir se adaptar à nova realidade dos processos e, mais recentemente ainda, dos inquéritos eletrônicos, virtuais. A primeira lei a caminhar na direção do processo virtual foi a Lei 9.800, de 1999, que regulamentou o envio de petições via fac-símile. Depois, com a Lei 10.259 de 2001, regrou-se a possibilidade de informatização de processos nos Juizados Especiais, mas sem muito efeito prático. Foi somente com a Lei 11.419, de 19 de dezembro de 2006 que se regulamentou a possibilidade do peticionamento eletrônico, inaugurando um modelo mais consistente de regramento da assinatura eletrônica que permitiu a paulatina substituição dos processos físicos por aqueles virtuais, com seu ápice 
de implantação em segundo grau de jurisdição verificado, na prática, apenas entre 2017 e $2018^{22}$.

A Lei $n^{\circ} 11.719 / 2008$, que deu nova redação ao artigo 405 do Código de Processo Penal e introduziu o $\S 1^{\circ}$, também contribuiu para consolidar a interpretação progressiva, de adaptação e atualização de significado à luz das novas tecnologias, da vetusta regra do artigo $9^{\circ}$ do $\mathrm{CPP}$, que, na prática, já vinha sendo adotada, ao se permitir "sempre que possível, o registro dos depoimentos do investigado, indiciado, ofendido e testemunhas será feito pelos meios ou recursos de gravação magnética, estenotipia, digital ou técnica similar, inclusive audiovisual, destinada a obter maior fidelidade das informações”.

A novidade mais recente está em inserir nesse universo eletrônico também o inquérito policial. Em paralelo ao desenvolvimento do processo eletrônico, criou-se o Sistema Nacional de Estatística de Segurança Pública e Justiça Criminal - SinespJC, em 2004, para difundir um modelo padronizado de registro de boletins de ocorrência. Esse modelo depois foi substituído pelo Sistema Nacional de Informações de Segurança Pública, Prisionais e sobre Drogas - SINESP, criado pela Lei n ${ }^{0} 12.681 / 12$. Mais recentemente, a Lei $\mathrm{n}^{0} 13.675$, de 11 de junho de 2018, institui o Sistema Único de Segurança Pública e o Sistema Nacional de Informações de Segurança Pública, Prisionais, de Rastreabilidade de Armas e Munições, de Material Genético, de Digitais e de Drogas. Todos esses regramentos, no entanto, preocupam-se com diretrizes programáticas e com o registro estatístico e não com a operacionalidade e documentação do inquérito policial no âmbito eletrônico. Nesse tema, o que se tem é ainda um certo amadorismo com algumas poucas experiências sendo implantadas em alguns Estados.

22 Neste percurso de mudança cultural no universo jurídico, uma das maiores dificuldades tem sido a falta de uniformização dos programas de computador utilizados pelos Tribunais, já que praticamente cada um possui um modelo diferente do outro (ex.: PJe, e-STF, e-STJ, Eproc, Projudi, etc.), exigindo de quem trabalha que possua diferentes navegadores em seu computador (ex.: Internet Explorer, Google Chrome, Mozila Firefox, Safari, etc.) e diversas versões de linguagem e plataformas de navegação (neste caso é dominante a linguagem Java, mas alguns programas exigem o Java atualizado e outros trabalham apenas com uma versão mais antiga do Java). 


\section{As INICIATIVAS PIONEIRAS DE IMPLANTAÇÃO DO INQUÉRITO POLICIAL ELETRÔNICO.}

Assim como se verificou com o processo penal o inquérito policial eletrônico pretende eliminar o papel, desmaterializando os registros e documentos relacionados à investigação criminal. Sucede que nesse tema ainda não há uniformidade de trato nacional e as vantagens da novidade dependem muito do modelo que se implementa em cada Estado.

A iniciativa embrionária de adoção do inquérito policial eletrônico se deu em 2016, com projetos quase concomitantes, um deles no Estado de São Paulo ${ }^{23}$ e, outro no plano federal, com o lançamento, em 21 de outubro de 2016, do Sistema de Gestão da Atividade de Polícia Judiciária (e-Pol), para implantação do inquérito policial eletrônico na Polícia Federal. Na justiça estadual, além de São Paulo, apenas outras quatro unidades federais utilizam os inquéritos policiais na forma eletrônica: Paraná, Goiás, Ceará e Distrito Federal.

Em novembro de 2018, o Estado de Goiás enviou cem inquéritos digitalizados ao Poder Judiciário e montou um laboratório para criar o modelo do inquérito policial eletrônico. O Sistema Integrado de Segurança Pública, que permite a comunicação entre sistemas da Secretaria de Segurança Pública e do Tribunal de Justiça, responsável pelo projeto no Estado, buscou simplificar a tramitação e medidas cautelares entre as duas instituições, e, também, trazer maior eficiência aos trabalhos da Polícia Civil. ${ }^{24}$

Também no início do mês de novembro de 2018, começou a tramitar o primeiro inquérito policial militar do Estado do Ceará. Segundo o Coronel Wilamar Galvão, coordenador da coordenadoria de Feitos Judiciários Militares, “após a realização de análises e reuniões sobre o assunto, foi constatada a grande necessidade de evoluir nesse campo,

23 Estado de São Paulo, Inquérito Policial Eletrônico. Disponível em: http://processoeletroniconobrasil.com.br/sp-inquerito-policial-eletronico/ acesso dia 26 de dezembro de 2019.

24 Polícia Federal do Estado de Goiás. Delegacia da cidade de Goiás envia $100^{\circ}$ inquérito digital ao poder judiciário. Disponível em: https://www.policiacivil. go.gov.br/drp/4a-regional/delegacia-da-cidade-de-goias-envia-100o-inquerito-digital-ao-poder-judiciario.html acesso: dia 8 de novembro de 2018 . fazer : 31 de dezembro de 2019. s em Brase, segurana uniformizados os estados que compoem 
pois havia grande desperdício de tempo, material e mão de obra para que fossem feitas as remessas dos IPM's anteriores.” ${ }^{25}$

Desde agosto de 2019, o Estado do Paraná implantou o inquérito policial eletrônico em todas as Comarcas do Estado, de forma integrada, tanto com o sistema informatizado de controle do Ministério Público ${ }^{26}$, quanto ao sistema Projudi, que regula o processo eletrônico no Judiciário ${ }^{27}$. Ainda em 2019, no mês de setembro, o Pleno do Tribunal Regional da $5^{\circ}$ Região aprovou a resolução $\mathrm{n}^{\circ} 8$ de 2019 , que trata da obrigatoriedade de inquéritos policiais e procedimentos criminais incidentais no sistema Processo Judicial Eletrônico (PJe), para todos os Estados que compõem a $5^{\circ}$ Região: Ceará, Pernambuco, Paraíba, Alagoas, Rio Grande do Norte e Sergipe. ${ }^{28}$ Nas metas para 2020, há uma proposta no Estado do Mato Grosso para implementar o sistema eletrônico.

Essas mudanças permitem tanto ao Ministério Público quanto à defesa uma maior participação na investigação, pois podem acompanhar a tramitação das investigações em tempo real sem precisar se deslocar até a delegacia para acessar os autos que estão disponibilizados a todo tempo. Além disso, no que diz respeito a segurança dos dados das investigações, o documento digital apresenta níveis muito superiores de segurança em comparação com o documento físico. ${ }^{29}$

25 Polícia Militar - Secretaria de Segurança Pública e Defesa Social. PMCE tramita o primeiro inquérito policial militar em formato digital. 9 de novembro de 2018. Disponível em: https://www.pm.ce.gov.br/2018/11/09/pmce-tramita-o-primeiro-inquerito-policial-militar-em-formato-digital/ acesso: dia 31 de dezembro de 2019.

26 Ministério Público do Paraná. Criminal, do Júri e Execuções Penais. Disponível em: http://www.criminal.mppr.mp.br/modules/conteudo/conteudo. php? conteudo $=2250$ acesso dia: 05 de janeiro de 2019.

27 Governo do Estado do Paraná. Polícia Civil participa na digitalização de inquérito policial. Disponível em: http://www.aen.pr.gov.br/modules/noticias/article.php?storyid=104783\&tit=Policia-Civil-participa-na-digitalizacao-de-inqueritos acesso: 26 de dezembro de 2019.

OAB Ceará. Inquéritos Federais da $5^{\circ}$ Região passarão a tramitar no PJe. 09 de setembro de 2019. Disponível em: http://oabce.org.br/2019/09/inqueritosfederais-da-5a-regiao-passarao-a-tramitar-no-pje/ acesso dia: 31 de dezembro de 2019.

29 MORAES, Rafael Francisco Marcondes de; ORTIZ, Luiz Fernando Zambrana. Inquérito Policial Eletrônico: tecnologia, garantismo e eficiência na 
Isso permite, também, um ganho econômico na operacionalização do sistema de justiça criminal, impactando numa redução orçamentária tanto para as polícias, quanto para o Judiciário, o Ministério Público e a Defensoria Pública, como se verá mais adiante.

É justamente esse o ponto que a implantação do inquérito policial eletrônico em todo o território nacional pode ser significativamente útil para a adaptação brasileira ao novo modelo do juiz das garantias, decorrência da Lei 13.964, de 24 de dezembro de 2019, que inseriu os artigos 3-A a 3-F no Código de Processo Penal brasileiro.

\section{A introdução do JUIz das garantias no Brasil}

O fundamento teórico da criação do juiz das garantias é evitar a contaminação psicológica que a análise dos requisitos de medidas cautelares na fase de investigação possa ter sobre o juiz de julgamento ${ }^{30}$. Assim, exigem-se diferentes juízes para a mesma persecução penal: um para a fase de investigação (o juiz das garantias) e outro para a fase processual (de instrução e julgamento).

Nos termos da nova lei, o juiz das garantias, ou seja, o juiz que será competente para a investigação criminal, "é responsável pelo controle da legalidade da investigação criminal e pela salvaguarda dos direitos individuais cuja franquia tenha sido reservada à autorização prévia do Poder Judiciário" e compete a ele: receber a comunicação imediata da prisão; receber o auto da prisão em flagrante para controle da legalidade; zelar pelos direitos do preso; ser informado sobre a instauração de qualquer investigação criminal; decidir sobre o requerimento de prisão provisória ou outra medida cautelar; prorrogar prisão provisória ou outra medida

investigação criminal. In: GIORDANI, Manoel Francisco de Barros da Motta Peixoto; MORAES, Rafael Francisco Marcondes de (Coord.). Estudos contemporâneos de polícia judiciária. São Paulo: Editora LTr, 2018, p. 83-96.

30 Sobre o tema, vide, dentre outros: LOPES JR., Aury; GLOECKNER, Ricardo

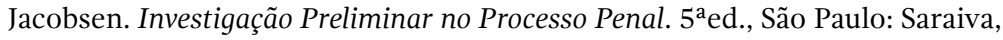
2013, pp. 404 e ss.; MAYA, André Machado. Imparcialidade e Processo Penal: da prevenção da competência ao juiz das garantias. $2^{\mathrm{a}}$ ed., São Paulo: Atlas, 2014, pp. 203 e ss.; ANDRADE, Mauro Fonseca. Juiz das Garantias. 2a ed., Curitiba: Juruá, 2015, passim. 
cautelar, bem como substituí-las ou revoga-las assegurando o contraditório e a ampla defesa; e também todas as demais decisões que forem referente a fase administrativa da investigação.

O novo regramento ainda reza que o juiz das garantias terá competência abrangida para todas as infrações penais (exceto de menor potencial ofensivo) e cessará a competência com o recebimento da denúncia ou queixa-crime, pois, com o recebimento da denúncia as questões pendentes serão decididas pelo juiz competente pela instrução e julgamento.

A nova regra do parágrafo único do art. $3^{\circ}-\mathrm{D}$, do Código de Processo Penal, prevê que "nas comarcas em que funcionar apenas um juiz, os tribunais criarão um sistema de rodízio de magistrados”. Esse é o ponto que tem gerado controvérsias, notadamente em razão de argumentação de natureza prática, voltada para a dificuldade operacional de sua implantação. A Associação dos Magistrados Brasileiros - AMB, por exemplo, emitiu nota pública, ingressou com ação direta de inconstitucionalidade e considerou a implementação do instituto inviável. Segundo a AMB um dos problemas da nova lei ocorrerá "nas comarcas onde apenas um magistrado se mantém encarregado da jurisdição, de modo que se o único magistrado da comarca atuar na fase do inquérito, ficará automaticamente impedido de jurisdicionar no processo, impondo-se o deslocamento de outro magistrado de comarca distinta, como sugere a Lei"31 E complementou: "além de essa medida acarretar aumento de despesas ao Judiciário, tanto por elevação do quadro de juízes e servidores quanto com gasto com deslocamentos e diárias dos magistrados que deverão atender outras comarcas, representa grandes riscos ao atendimento do princípio da razoável duração do processo nos locais."

Além da ação interposta pela AMB, foram ajuizadas outras três ações diretas de inconstitucionalidade ${ }^{32}$ no Supremo Tribunal Federal em face da lei 13.964/19, sobre o tema do juiz das garantias. O ministro Dias Toffoli, que se encontrava em plantão judicial, concedeu uma medida

31 Consultor jurídico. AMB alega que juiz das garantias pode prejudicar aplicação da Lei Maria da Penha. 10 de janeiro de 2020. Disponível em: https:// www.conjur.com.br/dl/clique-aqui-ler-integra-manifestacao-amb.pdf, acesso em 14 de janeiro de 2020.

32 As ações diretas de inconstitucionalidade propostas foram as $n^{0} 6.298, n^{\circ}$ $6.299, \mathrm{n}^{\circ} 6.300$ e $\mathrm{n}^{\circ} 6.305$. 
cautelar em resposta às ADIs 6.298, 6.299 e 6.300. Por sua vez o ministro relator, Luiz Fux, ao retornar à Corte no dia 22 de janeiro de 2020, proferiu nova decisão válida para as quatro ações diretas de inconstitucionalidade, ampliando a suspensão dos artigos relacionados ao juiz das garantias ${ }^{33}$.

Comparando as duas decisões se verifica certa divergência quanto à constitucionalidade dos dispositivos. $\mathrm{O}$ ministro Dias Toffoli entendeu pela constitucionalidade dos artigos $3^{\circ}-\mathrm{A}, 3^{\circ}-\mathrm{B}, 3^{\circ}-\mathrm{C}, 3^{\circ}-\mathrm{D}$, "caput", $3^{\circ}-\mathrm{E}$ e $3^{\circ}-\mathrm{F}$, e, pela inconstitucionalidade do parágrafo único do artigo $3^{\circ}-\mathrm{D}$. Acabou suspendendo a eficácia de todos eles por 180 dias, por apresentar violação ao poder de auto-organização constitucional (conferido ao Poder Judiciário). Por sua vez, o ministro Luiz Fux, revogou a decisão do então presidente da casa, pois interpretou como inconstitucional (ofensa direta ao artigo 96 da Constituição Federal) todos os artigos que tratam do tema, do artigo $3^{\circ}-\mathrm{A}$ ao $3^{\circ}$-F.

O presidente do STF fundamentou a sua decisão dizendo que o fazia sob a "ótica material", considerando que o juiz das garantias busca "densificar a exigência de imparcialidade do julgador", entendendo que não haveria uma reestruturação do Poder Judiciário, mas sim um aprimoramento funcional do juiz, na estrutura existente. Em contrapartida, o ministro relator, Luiz Fux, usando da mesma ótica de discussão constitucional material, reputou que os mesmos artigos $3^{\circ}$-B a $3^{\circ}-\mathrm{F}$ são inconstitucionais, fundamentando sua decisão em dois grupos de argumentos: "a ausência de dotação orçamentária e estudos de impacto prévios para implementação da medida e o impacto da medida na eficiência dos mecanismos brasileiros de combate à criminalidade". E afirmou que os artigos da reforma processual violam diretamente os artigos 169 e 99, da Constituição da República "na medida em que o primeiro dispositivo exige prévia dotação orçamentária para a realização de despesas por parte da União, dos Estados, do Distrito Federal, e o segundo garante autonomia orçamentária ao Poder Judiciário".

33 CHALFUN, Gustavo; OLIVEIRA JR, José Gomes de. Da análise do juiz das garantias sob a luz do direito comparado e das decisões liminares no STF. Migalhas, fevereiro de 2020. Disponível em: https://www.migalhas.com.br/ depeso/319989/da-analise-do-juiz-das-garantias-sob-a-luz-do-direito-comparado-e-das-decisoes-liminares-no-stf acesso dia: 23 de fevereiro de 2020. 
Dessa discussão toda, a regra que aqui merece destaque é a do parágrafo único do artigo $3^{\circ}-\mathrm{D}$, do Código de Processo Penal, considerando que é em relação a ela que se discute a violação quanto a auto -organização do Poder Judiciário e à inserção indevida do legislador na esfera orçamentária. Para bem compreender como essa discussão pode ser amenizada e até neutralizada com o uso da tecnologia, vale repetir o que consta do parágrafo único do art. $3^{\circ}$-D do Código de Processo Penal: "nas comarcas em que funcionar apenas um juiz, os tribunais criarão um sistema de rodízio de magistrados, a fim de atender às disposições deste Capítulo”.

Esse sistema de rodízio de magistrados pode ser desconsiderado na prática, caso se adote o modelo de inquérito policial eletrônico, já que, com ele, dispensa-se a presença física do juiz na mesma sede de comarca na qual se realiza a investigação e, assim, o juiz de uma comarca pode atuar, virtualmente, à distância, na fiscalização de inquéritos que tramitem com delegados sediados em outras comarcas. O interessante, então, é considerar que a adoção do inquérito policial eletrônico torna obsoleta a discussão quanto à constitucionalidade, ou não, do parágrafo único do artigo $3^{\circ}-\mathrm{D}$, do Código de Processo Penal.

E mais do que isso: é preciso resgatar a possibilidade de realização da audiência de custódia, pelo juiz das garantias, mediante videoconferência. Não há mais como seguir sustentando - como se fazia nos anos 1990 - a inconstitucionalidade das videoconferências. Nem mesmo a invocação do artigo $7^{\circ}$, item 5 , da Convenção Americana de Direitos Humanos, que diz que "toda pessoa detida ou retida deve ser conduzida, sem demora, à presença de um juiz (...)”, serve como argumento impeditivo para adoção da videoconferência. Quando se fala "à presença de um juiz" não se quer exigir que seja física. É preciso considerar que a Convenção é de 1969, ou seja, de uma época na qual falar em videoconferência soava como ficção científica. Numa interpretação progressiva dessa regra, é preciso atualizar e adaptar seus sentidos à luz da tecnologia e em favor do preso, inclusive. A adoção da videoconferência em comarcas de interior, de difícil acesso, acelera o procedimento de avaliação do flagrante e permite a soltura do preso em tempo que lhe favorece. Vale, também, referir à lição de Fauzi Hassan Choukr quando esclarece que o uso da videoconferência para interrogatório "não sofre 
censura de Cortes internacionais protetivas de direitos fundamentais sendo empregada com regularidade na Europa continental" 34 .

Não bastasse, hoje, a defesa técnica é duplamente assegurada - dois defensores são exigidos (um ao lado do juiz e outro ao lado do preso) -; a oralidade existe em tempo real; o preso vê ao juiz e este a ele; captam suas expressões faciais e reações físicas, enfim, a imediatidade da fala é observada. As duas únicas coisas que o juiz não faz na videoconferência é tocar no preso e sentir seu cheiro. As duas, não é demais destacar, não prejudicam o preso e sua audiência de custódia. Não há, portanto, violação alguma de direitos e garantias constitucionais e andou mal aqui o legislador ao querer cercear essa possibilidade na reforma do "pacote anticrime".

Seja como for, a ideia de vedar a realização de videoconferência do preso na audiência de custódia foi vetada pelo Presidente da República, o que permite ao juiz das garantias, responsável também pela audiência de custódia, usar igualmente aqui a tecnologia em favor do preso, evitando seu deslocamento físico e ouvindo-o por videoconferência.

Por fim, a discussão em torno do orçamento do Poder Judiciário, do Ministério Público e da Defensoria Pública, também ficaria esvaziada, pois, além da implantação do inquérito policial eletrônico ser uma questão que envolve o orçamento do Poder Executivo, já que as polícias civis são a ele subordinadas, não se trataria mais da contratação de novos juízes, promotores e defensores públicos, pois todos podem atuar à distância. Até mesmo o custo, em comparação às duas possíveis soluções - manter o que propõe o parágrafo único do artigo $3^{\circ}-\mathrm{D}$ ou adotar o inquérito policial eletrônico - pende em favor da solução tecnológica.

\section{VANTAGENS ECONÔMICAS DO INQUÉRITO POLICIAL ELETRÔNICO}

Considerando que uma das preocupações que gira em torno da implantação do juiz das garantias é o custo que isso poderia gerar em razão de boa parte das Comarcas do interior contarem com apenas um juiz, é certo que a adoção do inquérito policial eletrônico também pode

34 CHOUKR, Fauzi Hassan. Iniciação ao Processo Penal. Florianópolis: Empório do Direito, 2015, pp. 80-81. 
contribuir para diminuir sensivelmente esse custo, se comparado à ideia de contratação de novos juízes, promotores, delegados e defensores públicos, e seus respectivos deslocamentos físicos de uma comarca à outra.

Como exemplo do barateamento levado pela digitalização, a Secretaria de Segurança Pública do Estado do Mato Grosso, em julho de 2019, apontou que a implantação do modelo exige um investimento de cerca de 3 (três) milhões de reais, incluindo a aquisição de equipamentos (tais como: leitores biométricos, assinaturas digitais, discos de armazenamento, servidores, entre outros), mas gera uma economia anual de cerca de 2 (dois) milhões de reais, apenas com a eliminação de impressões, papel e combustível. Ou seja, em um ano e meio é possível recuperar o investimento ${ }^{35}$.

Em São Paulo, o valor gasto para implantação do inquérito policial eletrônico, em 2015, foi de 1,2 milhões de reais em certificação eletrônica para os policiais e 1,5 milhões de reais em tecnologia. Na época, estimava-se média de gasto dos inquéritos na forma tradicional (física) em torno de 27 milhões de reais ao ano ${ }^{36}$. Desse montante, a economia anual, apenas em folha de papel, girava em torno de 14 milhões, pois em média, a Polícia Civil do Estado de São Paulo instaurava 70 (setenta) mil inquéritos ao ano, cada um deles com cerca de 200 (duzentas) laudas. $\mathrm{Na}$ implementação do sistema foi necessária uma equipe enxuta, de oito pessoas na implantação e outras doze no desenvolvimento. ${ }^{37}$

Além disso, segundo o delegado Joaquim Leitão Júnior, o sistema foi testado na Delegacia de Defesa da Mulher (DDM) de São Paulo e comprovou-se que, com o inquérito na forma eletrônica, os casos de flagrantes, solicitações de medidas protetivas da Lei Maria da

35 ESTADO DO MATO GROSSO. O inquérito policial eletrônico vai gerar economia anual de R\$ 2 milhões. Secretaria de Estado de Segurança Pública (SESP), 2019. Disponível em: http://www.sesp.mt.gov.br/-/inquerito-policial-eletronico-vai-gerar-economia-anual-de-r-2-milhoes acesso dia 24 de fevereiro de 2020.

36 ESTADO DE SÃO PAULO. Poder Legislativo. Diário oficial. Disponível em: http://www.arquivoestado.sp.gov.br/site/assets/institucional/relatorios/ relatorio_apesp_2017.pdf acesso em: 27 de fevereiro de 2020.

37 ORTIZ, Luiz Fernando Zambrana. Inquérito Policial Eletrônico. Disponível em: https://www.premioinnovare.com.br/praticas/9365 acesso em: 27 de fevereiro de 2020 . 
Penha e cautelares, a exemplo das representações de prisão preventiva e de intercepção telefônica, passaram a ser encaminhadas com imediatismo para avaliação do juiz, o que possibilita que as decisões sejam tomadas e despachadas rapidamente, como o caso reclama. ${ }^{38}$ Esse dado é interessante pois ameniza a força de outro argumento lançado na nota da Associação Brasileira de Magistrados, quando considerou que a adoção do juiz das garantias prejudicaria "o epidêmico número de casos de feminicídio existentes hoje no Brasil, bem como que o escopo de incidência da Lei Maria da Penha é, principalmente, uma atuação cautelar durante a fase inquisitorial, vislumbra-se um alarmante retrocesso da legislação brasileira quanto à conquista histórica em termos de coibição e prevenção da violência doméstica e familiar contra a mulher no país." ${ }^{39}$

O sucesso que advirá da implantação nacional do inquérito policial em sua forma eletrônica em todos os Estados da federação, pode ser considerado, por analogia, àquele que vem sendo experimentado com a adoção do processo penal eletrônico em todo o país. Levando-se em conta os dados compilados pelo Conselho Nacional de Justiça (CNJ), que preveem indicadores de desempenho e informatização, desde 2009, dos processos eletrônicos, a média de casos que passaram a tramitar em forma eletrônica pelo Poder Judiciário em âmbito nacional, aumentou significativamente, de 2009 a 2018, saindo de praticamente zero para $78 \%$ dos processos, em $2^{\circ}$ grau, e $84,8 \%$ em $1^{\circ}$ grau. ${ }^{40}$

38 LEITÃO JR. Joaquim. O inquérito policial eletrônico e os desafios da polícia no futuro. Disponível em: http://genjuridico.com.br/2017/12/13/inquerito-policial-eletronico-policia-judiciaria-do-futuro/ acesso em: $27 \mathrm{de} \mathrm{fev.} \mathrm{de}$ 2020.

39 ASSOCIAÇÃO DOS MAGISTRADOS BRASILEIROS - AMB. Implementação do juiz das garantias é inviável e causará prejuízos à aplicação da Lei Maria da Penha. Disponível em: https://www.amb.com.br/implementacao-do-juizdas-garantias-e-inviavel-e-causara-prejuizos-aplicacao-da-lei-maria-da-penha/?doing_wp_cron=1582818267.7870318889617919921875 acesso dia 27 de fev. de 2020.

40 BRASIL. Conselho Nacional de Justiça. Justiça em Números 2019. Disponível em: https://www.cnj.jus.br/wp-content/uploads/conteudo/arquivo/2019/08/justica_em_numeros20190919.pdf acesso em: 27 de fevereiro de 2020, p. 116-118. 
Ainda considerando o processo eletrônico, o CNJ indica que as justiças estaduais possuem variação de adaptação nesses dez anos. Entre os Estados que contam com $100 \%$ de processos virtuais, em $1^{\circ}$ grau, encontram-se: São Paulo; Tocantins; Mato Grosso do Sul; Amazonas; Alagoas; Acre e Sergipe. Entre 70\% e 99\% estão: Paraná (99\%); Santa Catarina (98\%); Bahia (97\%); Roraima (96\%); Amapá (94\%); Paraíba (94\%); Rio de Janeiro (92\%); Goiás (87\%); Piauí (87\%); Rio Grande do Norte (85\%); Pernambuco (85\%); Mato Grosso (83\%); Rondônia (81\%); Distrito Federal (74\%); e Maranhão (72\%). Variando entre 35\% a 70\% estão: Pará (65\%); Ceará (61\%); Minas Gerais (42\%); Rio Grande do Sul (41\%); e Espírito Santo (38\%). Observa-se que em $1^{\circ}$ grau não há indicativo de Estado com $100 \%$ de processos tramitando na forma física. Já em $2^{\circ}$ grau, com $100 \%$ de tramitação eletrônica a realidade é similar, com média de $72 \%$ de implantação, com um único destaque negativo de zero por cento para o Espírito Santo. ${ }^{41}$

Isso significa dizer que em apenas dez anos de colocação em prática do processo eletrônico, boa parte do país já conta uma estrutura de comunicação, via internet, entre as Comarcas do interior e os Tribunais e que essa mesma estrutura pode ser utilizada para viabilizar a integração do inquérito policial eletrônico.

Além disso, segundo consta no relatório do último relatório analítico "Justiça em Números", do CNJ, em 2018, as despesas totais do Poder Judiciário somaram 93,7 bilhões de reais. Ressalte-se que 18\% deste gasto é referente a inativos (previdenciário, em aposentadorias e pensões). Dito isso, as despesas, por magistrado, representam uma média mensal de, aproximadamente, 46 mil reais. Registra-se, ainda, que a soma do imposto de renda (até $27,5 \%$ ) com a previdência social (11\%), ambos incidentes sobre a remuneração total, a depender da data de ingresso no funcionalismo público, podem gerar impacto de quase $40 \%$ na folha de pagamento. ${ }^{42}$ Como solução para o problema das comarcas de juiz

41 BRASIL. Conselho Nacional de Justiça. Justiça em Números 2019. Disponível em: https://www.cnj.jus.br/wp-content/uploads/conteudo/arquivo/2019/08/justica_em_numeros20190919.pdf acesso em: 27 de fevereiro de 2020, p. 116-118.

42 BRASIL. Conselho Nacional de Justiça. Justiça em Números 2019. Disponível em: https://www.cnj.jus.br/wp-content/uploads/conteudo/arquivo/2019/08/ 
único, o custo para contratação de novos magistrados, portanto, seria muito mais impactante do que a solução tecnológica de implantação do inquérito policial eletrônico.

Por fim, cabe lembrar que o custo da implementação do inquérito policial na forma eletrônica é debitada ao orçamento do Poder Executivo, uma vez que as Polícias Civis são a ele subordinadas. Esse aspecto, inclusive, permite dizer que a discussão em torno da constitucionalidade, ou não, do artigo $3^{\circ}$-D, que está posta perante o Supremo Tribunal Federal, não interessa para a solução aqui proposta. Em outras palavras: mesmo que se venha a considerar o artigo $3^{\circ}$-D do Código de Processo Penal como inconstitucional, porque estaria obrigando o orçamento do Poder Judiciário, sem iniciativa legislativa deste, como constou da decisão liminar do ministro Fux, o custo de implantação do inquérito policial eletrônico escapa à essa discussão, pois é relacionado ao orçamento do Poder Executivo.

Assim, o único impacto real que a adoção nacional do inquérito policial eletrônico traria, seria de redução de custos, tanto para o Poder Executivo na tramitação dos inquéritos (com a redução de gastos com papel, servidores, deslocamentos físicos dos delegados e dos escrivães), quanto para o Poder Judiciário, Ministério Público e Defensoria Pública, na viabilização do juiz das garantias sem a necessidade de novas contratações e pagamentos de diárias com deslocamentos de juízes, promotores e defensores públicos.

\section{Considerações Finais}

As críticas da Associação dos Magistrados Brasileiros em torno da implantação do juiz das garantias, notadamente voltadas para a dificuldade prática nas Comarcas de juiz único e para o custo de contratação de novos magistrados, podem ser suplantadas através das soluções apresentadas para o inquérito policial eletrônico.

Com o inquérito policial eletrônico poderá ser realizada a juntada de documentos e fiscalização de atos da investigação em tempo real, além

justica_em_numeros20190919.pdf acesso em: 27 de fevereiro de 2020,p. 62 e ss. 
disso qualquer magistrado, em qualquer lugar do país, terá condição de acompanhar, mesmo à distância, o que se produz na investigação. Qualquer medida cautelar pode ser, portanto, analisada e decidida virtualmente.

Complementa-se que não há restrições legislativas para a realização de audiências de custódia por videoconferência, o que permitiria suprir o deslocamento físico do magistrado para as comarcas menores, com juízes únicos, sem abrir mão das garantias constitucionais do custodiado. O mesmo se dá nos demais casos onde haja necessidade de audiência com o magistrado (v.g. habeas corpus e produção antecipada de provas urgentes), a qual pode ser realizada por videoconferência.

É claro que a efetivação juiz das garantias não depende da implantação do inquérito policial eletrônico, mas é certo que ele atenua as críticas aos custos de contratação de novos magistrados, promotores, delegados e defensores públicos, afastando, em igual proporção, os reclamos de gastos com diárias nos deslocamentos físicos desses atores processuais, no modelo tradicional.

Os custos de implantação do modelo de inquérito policial eletrônico são, também, significativamente menores em comparação com a pretensão de contratação de novos juízes, promotores, delegados e defensores públicos. Além de ser possível aproveitar todo o cabeamento e interligação de redes de internet já existente em boa parte das comarcas do país para funcionalização do processo penal eletrônico, o custo de ampliação dessas redes de conexão para incorporar o inquérito policial virtual seria arcado pelo Poder Executivo e não pelo Judiciário. No âmbito federal já está em funcionamento o inquérito policial eletrônico. Com isso, também se esvazia a discussão de inconstitucionalidade do parágrafo único do artigo $3^{\circ}-\mathrm{D}$, do Código de Processo Penal, pois ela deixa de envolver a ingerência do Poder Legislativo na auto-gestão do Poder Judiciário e em sua autonomia orçamentária, como vem sendo discutido nas ADIs propostas no Supremo Tribunal Federal.

Conclui-se que com uma adequada implementação do inquérito policial eletrônico se permitirá agilizar e tornar mais transparentes os procedimentos do inquérito policial. A virtualização desta fase permitirá a implementação do Juiz das Garantias, atendendo ao novo regramento de uma forma mais econômica e contribuindo para o aprimoramento do Estado Democrático de Direito. 


\section{REFERÊNCIAS}

AJOUZ, Alessandro. Obre o Juízo das Garantias, conforme a lei 13.964/19. 01 de janeiro de 2020. Disponível em: https://www.migalhas.com.br/dePeso/16,MI317629,101048-Sobre+o+juizo+das+garantias+conforme+a+lei+1396419 acesso: dia 02 de janeiro de 2020 .

ALMEIDA, Romeu de. JUNIOR, Salles. Inquérito Policial e Ação Penal. São Paulo: Editora Saraiva, $7^{\circ}$ ed., 1998.

ANDRADE, Mauro Fonseca. Juiz das Garantias. 2a ed., Curitiba: Juruá, 2015.

BARBOSA, Manoel Messias. Inquérito Policial. São Paulo: Editora Método. $4^{\circ}$ ed., 2004.

BARBOSA, Marialva. História Cultural da Imprensa. Brasil. 1900-2000. Rio de Janeiro: Mauad, 2007.

CADENA, Nelson Váron. O impacto das máquinas de escrever nas redações. In: Portal Imprensa. 27 de outubro de 2008, disponível em http://portalimprensa.com. $\mathrm{br} /$ noticias/opiniao/311/o+impacto+da+maquina+de+escrever+nas+redacoes, acesso em 14 de janeiro de 2020.

CHOUKR, Fauzi Hassan. Código de Processo Penal: comentários consolidados e crítica jurisprudencial. $3^{\mathrm{a}}$ ed., São Paulo: Saraiva, 2009.

CHOUKR, Fauzi Hassan. Iniciação ao Processo Penal. Florianópolis: Empório do Direito, 2015.

FURTADO, Vasco. Tecnologia e Gestão da Informação na Segurança Pública. São Paulo: Garamond, 2002.

HOFFMANN, Henrique. Prazo de conclusão do inquérito serve para proteção do suspeito. Disponível em: https://www.conjur.com.br/2018-out-31/academia -policia-prazo-conclusao-inquerito-existe-protecao-suspeito acesso dia: 07 de novembro de 2019.

LOPES JR., Aury; GLOECKNER, Ricardo Jacobsen. Investigação Preliminar no Processo Penal. 5aed., São Paulo: Saraiva, 2013.

MAYA, André Machado. Imparcialidade e Processo Penal: da prevenção da competência ao juiz das garantias. $2^{\mathrm{a}}$ ed., São Paulo: Atlas, 2014. 
MORAES, Rafael Francisco Marcondes de; ORTIZ, Luiz Fernando Zambrana. Inquérito Policial Eletrônico: tecnologia, garantismo e eficiência na investigação criminal. In: GIORDANI, Manoel Francisco de Barros da Motta Peixoto; MORAES, Rafael Francisco Marcondes de (Coord.). Estudos contemporâneos de polícia judiciária. São Paulo: Editora LTr, 2018.

SILVA, José Geraldo da. O inquérito policial e a polícia judiciária. Campinas: Editora Bookseller, 2000.

SILVA, Rita de Cássia Lopes da. Direito Penal e Sistema Informático. São Paulo: RT, 2003.

SOARES, Rafael. Delegacia da Baixada Fluminense ainda usa máquina de escrever e tem mofo nas paredes. In: Jornal Extra. Edição de 31 de março de 2013, disponível em https://extra.globo.com/casos-de-policia/delegacia-da-baixada-fluminense -ainda-usa-maquina-de-escrever-tem-mofo-nas-paredes-7985826.html, acesso em 14 de janeiro de 2020.

SUSSEKIND, Flora. Cinematógrafo de Letras: literatura, técnica e modernização no Brasil. São Paulo: Companhia das Letras, 1987.

ZELLERS, John Adam. The Typewriter. A short History on its 75th Anniversary, 1873-1948. New York: Newcomen Society of England. American Brench, 1948. 


\section{Informações adicionais e declarações dos autores (integridade científica)}

Declaração de conflito de interesses (conflict of interest declaration): os autores confirmam que não há conflitos de interesse na realização das pesquisas expostas e na redação deste artigo.

Declaração de autoria e especificação das contribuições (declaration of authorship): todas e somente as pessoas que atendem os requisitos de autoria deste artigo estão listadas como autores; todos os coautores se responsabilizam integralmente por este trabalho em sua totalidade.

- Rodrigo Régnier Chemim Guimarães: projeto e esboço inicial (conceptualization), desenvolvimento da metodologia (methodology), coleta e análise de dados (data curation), levantamento bibliográfico (investigation), revisão bibliográfica (investigation), redação (writing - original draft), participação ativa nas discussões dos resultados (validation), revisão crítica com contribuições substanciais (writing review and editing), aprovação da versão final.

- Sarah Gonçalves Ribeiro: coleta e análise de dados (data curation), levantamento bibliográfico (investigation), revisão bibliográfica (investigation), redação (writing - original draft), participação ativa nas discussões dos resultados (validation), revisão crítica com contribuições substanciais (writing - review and editing), aprovação da versão final.

Declaração de ineditismo e originalidade (declaration of originality): os autores asseguram que o texto aqui publicado não foi divulgado anteriormente em outro meio e que futura republicação somente se realizará com a indicação expressa da referência desta publicação original; também atestam que não há plágio de terceiros ou autoplágio. 
Dados do processo editorial

(http://www.ibraspp.com.br/revista/index.php/RBDPP/about/editorialPolicies)

- Recebido em: 15/01/2020

Equipe editorial envolvida

- Controle preliminar e verificação de plágio:

- Editor-chefe: 1 (VGV) 19/01/2020

- Avaliação 1: 27/01/2020

- Editora-associada: 1 (MSG)

- Avaliação 2: 01/02/2020

- Revisores: 3

- Avaliação 3: 05/02/2020

- Decisão editorial preliminar: 21/02/2020

- Retorno rodada de correções: 28/02/2020

- Decisão editorial final: 29/02/2020

\section{COMO CITAR ESTE ARTIGO:}

GUIMARÃES, Rodrigo R. C.; RIBEIRO, Sarah G. A introdução do juiz das garantias no Brasil e o inquérito policial eletrônico. Revista Brasileira de Direito Processual Penal, Porto Alegre, vol. 6, n. 1, p. 147-174, jan./abr. 2020. https://doi.org/10.22197/rbdpp.v6i1.329

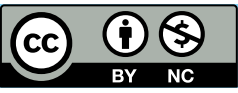

Esta obra está licenciada com uma Licença Creative Commons Atribuição-NãoComercial 4.0 Internacional. 